\title{
Nitric oxide promotes p53 nuclear retention and sensitizes neuroblastoma cells to apoptosis by ionizing radiation
}

\author{
$X$ Wang $^{1}$, A Zalcenstein ${ }^{1}$ and $M$ Oren $^{\star, 1}$ \\ ${ }^{1}$ Department of Molecular Cell Biology, Weizmann Institute of Science, \\ Rehovot, Israel \\ * Corresponding author: M Oren, Department of Molecular Cell Biology, \\ Weizmann Institute of Science, 300 Herzl Street, Rehovot 76100, Israel. \\ Tel: +1 9728 9342358; Fax: +1972 8 9346004; \\ E-mail: moshe.oren@weizmann.ac.il
}

Received 23.7.02; revised 20.9.02; accepted 16.10 .02 Edited by G Melino

\begin{abstract}
Nitric oxide (NO) is a potent activator of the p53 tumor suppressor protein. However, the mechanisms underlying p53 activation by $\mathrm{NO}$ have not been fully elucidated. We previously reported that a rapid downregulation of Mdm2 by NO may contribute to the early phase of p53 activation. Here we show that NO promotes $\mathrm{p} 53$ nuclear retention and inhibits Mdm2mediated p53 nuclear export. NO induces phosphorylation of p53 on serine 15, which does not require ATM but rather appears to depend on the ATM-related ATR kinase. An ATRkinase dead mutant or caffeine, which blocks the kinase activity of ATR, effectively abolishes the ability of NO to cause p53 nuclear retention, concomitant with its inhibition of p53 serine 15 phosphorylation. Of note, $\mathrm{NO}$ enhances markedly the ability of low-dose ionizing radiation to elicit apoptotic killing of neuroblastoma cells expressing cytoplasmic wild-type p53. These findings imply that, through augmenting p53 nuclear retention, NO can sensitize tumor cells to p53-dependent apoptosis. Thus, NO donors may potentially increase the efficacy of radiotherapy for treatment of certain types of cancer. Cell Death and Differentiation (2003) 10, 468-476. doi:10.1038/ sj.cdd. 4401181
\end{abstract}

Keywords: p53; nitric oxide (NO); ATR; nuclear export; neuroblastoma

Abbreviations: NO, nitric oxide; NOS, nitric oxide synthases; NES, nuclear export signal; PARP, Poly(ADP-Ribose) Polymerase 1 ; NLS, nuclear localization signals; LMB, lyptomycin $B$

\section{Introduction}

Nitric oxide (NO) is an important bioactive molecule, which exerts diverse and sometimes opposing biological effects. On the one hand, NO can mediate many beneficial physiological processes such as protective cell killing by macrophages, vasodilation and various sorts of neurotransmission. On the other hand, elevated concentrations of NO can be detrimental to cells because of the induction of inactivating protein modifications, lipid oxidation, and DNA strand breaks. ${ }^{1-3} \mathrm{NO}$ may potentially affect every type of mammalian cells, owing to its ubiquitous production in the body. ${ }^{4} \mathrm{NO}$ is mainly formed by specific NO synthases (reviewed in Zweier et al. ${ }^{5}$ ). NO generation is connected to stress responses through the fact that one of the NO synthases, iNOS (also known as NOSII) is stress inducible. In the context of carcinogenesis, this is particularly important in view of the fact that low oxygen and low $\mathrm{pH}$, which induce iNOS expression effectively, ${ }^{6,7}$ are characteristic features of the tumor microenvironment.

The p53 tumor suppressor gene plays a major role in the prevention of cancer, and is subject to mutational inactivation in a large fraction of human tumors (for some recent p53 reviews see ${ }^{8-13}$ ). Under normal conditions, p53 is a shortlived protein owing to its fast proteasomal degradation. This degradation is mediated largely by one of p53's own target gene products, Mdm2, which serves as an E3 ubiquitin ligase for $p 53,{ }^{14-18}$ although Mdm2-independent pathways for $\mathrm{p} 53$ degradation also exist. ${ }^{19}$ This $\mathrm{p} 53-\mathrm{Mdm} 2$ negative feedback loop functions as an effective device for restraining p53 activity in the absence of oncogenic stress. ${ }^{9}$ Different types of stress engage different mechanisms to evoke a p53 response, through disrupting the p53-Mdm2 feedback loop. ${ }^{20,21}$ This disruption can be achieved by reducing the p53-Mdm2 binding affinity, for instance, via phosphorylation on p53 on serine 20 as is the case of ATM and Chk2dependent DNA damage signalling, by attenuation of Mdm2 function through covalent modifications, or by inactivation of Mdm2's E3 ubiquitin ligase activity as occurs upon ARF binding to Mdm2 in the case of aberrant oncogenic stimuli. ${ }^{22-}$ ${ }^{26}$ In addition, ATM-dependent phosphorylation of p53 on Serine 15 was reported to inactivate a nuclear export signal (NES) located within the N-terminal domain of p53, thereby contributing to $p 53$ nuclear retention and probably also to p53 activation. $^{27}$

Activation of p53 by NO has been observed in many cell types. ${ }^{28-33}$ NO-induced p53 contributes to various cell typespecific biological effects of NO, such as induction of apoptosis and inhibition of proliferation. ${ }^{28,34}$ Most significantly, the crosstalk between NO and p53 is likely to play an important role in tumor suppression and in carcinogenesis. ${ }^{35-37}$ However, the molecular mechanisms underlying the induction of $p 53$ by NO have not been fully elucidated. We recently reported that NO signalling to p53 is independent of ATM, PARP-1 (Poly(ADP-Ribose) Polymerase 1) and ARF. ${ }^{38}$ Induction of p53 by NO is preceded by a rapid decrease in Mdm2 protein, which may enable the initial rise in p53 levels early after exposure to $\mathrm{NO}^{38}$ We now show that NO is a potent inducer of p53 nuclear retention by inhibiting p53 nuclear export. This effect of NO appears to require the ATMrelated kinase ATR. Of note, NO can sensitize neuroblastoma 
cells to killing by low doses of ionizing radiation; this may have potential application to radiotherapy of certain types of neuroblastoma, and perhaps other human tumors harboring cytoplasmic wtp53.

\section{Results}

\section{NO promotes p53 nuclear retention}

p53 possesses nuclear localization signals (NLSs) and nuclear export signals (NESs), enabling it to shuttle between the nucleus and the cytoplasm. ${ }^{27,39-41}$ The impact of NO on p53 nucleocytoplasmic shuttling was investigated in Clone 6 cells, rat embryo fibroblasts stably expressing a temperaturesensitive mouse p53 mutant (tsp53) that exhibits substantial cytoplasmic localization at the nonpermissive temperature of $37^{\circ} \mathrm{C} .^{42,43}$ This cell line offers several advantages, in that the abundant expression of the tsp53 allows easy detection of both cytoplasmic and nuclear $\mathrm{p} 53,{ }^{43}$ and particularly that the total p53 protein levels do not change significantly upon GSNO treatment (see Figure 2a). When Clone 6 cells, grown at $37^{\circ} \mathrm{C}$, were treated for $12 \mathrm{~h}$ with lyptomycin $\mathrm{B}(\mathrm{LMB})$, a specific and irreversible inhibitor of CRM1/exportin1, the tsp53 became completely nuclear (Figure 1a, left panel), implying that the cytoplasmic localization in the control untreated cells (Ctr) is largely because of excessive nuclear export rather than complete blockage of nuclear import. Remarkably, exposure of Clone 6 cells to $1 \mathrm{mM} \mathrm{GSNO}$ for $12 \mathrm{~h}$ (Figure 1a, left panel) or to as a low concentration as $100 \mu \mathrm{M}$ GSNO for $10 \mathrm{~h}$ also resulted in unequivocal nuclear retention of the tsp53 (Figure 1a, right panel). Thus, like LMB, NO is also capable of inhibiting the nuclear export of p53.

Although very useful as an experimental model, Clone 6 cells represent an artificial system generated by transfection with a mutant form of p53. It was therefore important to evaluate whether NO can also affect the nucleocytoplasmic shuttling of authentic wtp53. To that end, we took advantage of IMR32 human neuroblastoma cells, which expresses wtp53 that is mostly localized to the cytoplasm. ${ }^{44,45}$ Consistent with the conclusion that this p53 is subject to excessive nuclear export, ${ }^{41}$ treatment of IMR32 cells with LMB for $10 \mathrm{~h}$ results in effective trapping of their p53 in the nucleus (Figure 1b). As shown in Figure 1b, GSNO was also very effective in inducing nuclear retention of p53 in IMR32 cells. The effect of NO occurred quite rapidly, with a significant change in p53 localization seen already within $2 \mathrm{~h}$ and complete nuclear retention attained within $4 \mathrm{~h}$ of $\mathrm{NO}$ treatment (Figure $1 \mathrm{~b}$ ). Similar results were also obtained in experiments employing a a

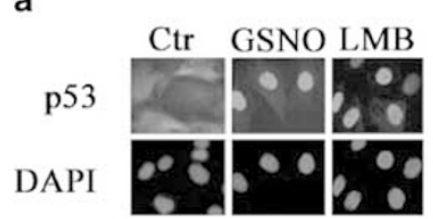

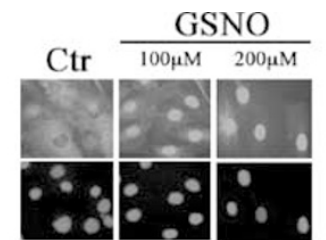

b

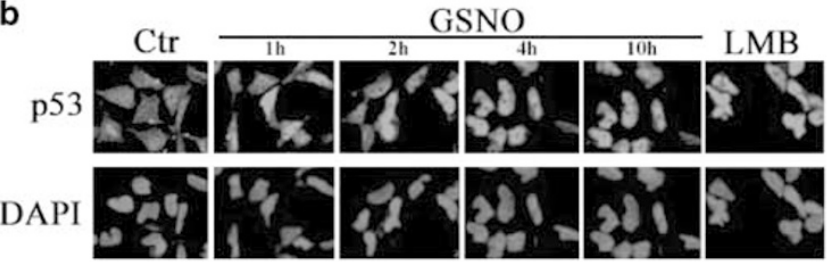

C

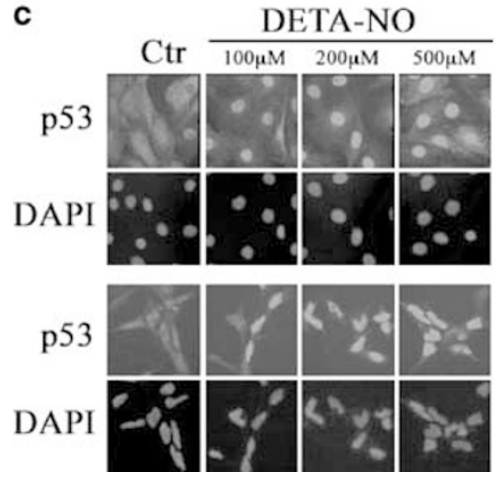

d
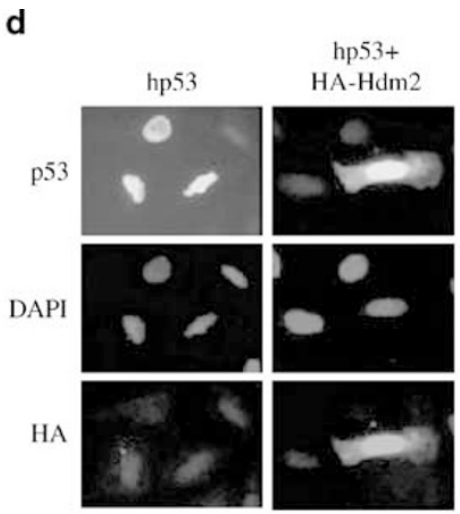

hp53+

HA-Hdm2

hp53+ + GSNO

$\mathrm{HA}-\mathrm{Hdm} 2$

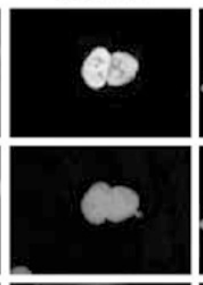
$+\mathrm{LMB}$

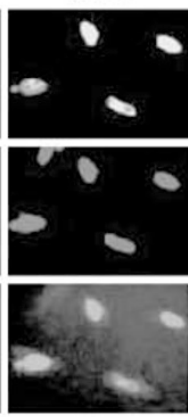

e

- nuclear

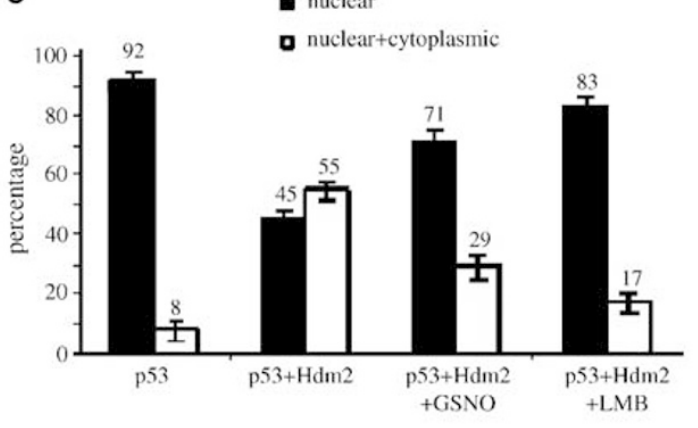

Figure 1 GSNO causes nuclear retention of tsp53 and wtp53. (a) Clone 6 cells were cultured at $37^{\circ} \mathrm{C}$ in the presence of 100 or $200 \mu \mathrm{M} \mathrm{GSNO}$ (right panel), $1 \mathrm{mM}$ GSNO (left panel), or $10 \mathrm{ng} / \mathrm{ml}$ LMB, for $12 \mathrm{~h}$ (right panel) or $10 \mathrm{~h}$ (left panel). p53 was visualized by immunofluorescence microscopy (IF) with polyclonal antibody CM5. The nucleus was visualized with DAPI. (b) IMR32 human neuroblastoma cells were cultured in the presence of $1 \mathrm{mM}$ GSNO or LMB (10 ng/ml) for different periods of time. p53 was visualized by IF with polyclonal antibody CM1. (c) Clone 6 cells (upper panel) or IMR32 cells (lower panel) were cultured for $10 \mathrm{~h}$ at $37^{\circ} \mathrm{C}$ in the presence of the indicated concentrations of DETA-NO. IF of p53 was performed with CM1 (lower panel) or CM5 (upper panel). (d) U2-OS cells, grown in $6 \mathrm{~cm}$ dishes, were transfected with a p53 expression plasmid $(0.5 \mu \mathrm{g})$, with or without $4 \mu \mathrm{g}$ of plasmid encoding HA-Hdm2. At $20 \mathrm{~h}$ after transfection cells were treated with $1 \mathrm{mM}$ GSNO or $20 \mathrm{ng} / \mathrm{ml} \mathrm{LMB}$ for $12 \mathrm{~h}$. IF of p53 and HA-Hdm2 was performed with a mixture of the p53-specific monoclonal antibodies DO-1 and PAb1801, and a polyclonal anti-HA antibody (Santa Cruz), respectively. (d) Cells in multiple fields from the experiment shown in (c) were counted. The figure shows a statistical analysis of the percentage of cells with only nuclear p53 or with both nuclear and cytoplasmic p53 
structurally different NO donor, DETA-NO, which releases NO in solution with slow kinetics and without producing toxic metabolites. ${ }^{46}$ As shown in Figure 1c, exposure to DETA-NO for $10 \mathrm{~h}$, at concentrations as low as $100 \mu \mathrm{M}$, resulted in clear nuclear retention of both tsp53 (Clone 6 cells) and wtp53 (IMR32 cells).

Since p53 nuclear export can be promoted by Mdm2, ${ }^{47-49}$ we asked whether NO can interfere with this effect of Mdm2. To that end, U2-OS human osteosarcoma cells were transiently transfected with p53, either alone or together with Mdm2. In the absence of cotransfected Mdm2, p53 was localized almost exclusively to the nucleus (Figure 1d, hp53, and Figure 1e). In agreement with earlier reports, ${ }^{48,49}$ cotransfection of Mdm2 caused a dramatic increase in the number of U2-OS cells displaying both nuclear and cytoplasmic p53 (Figure 1d, hp53+HA-Mdm2, and Figure 1e). However, the ability of Mdm2 to drive p53 from the nucleus into the cytoplasm was significantly impaired by the presence of GSNO, even though the effect was not as pronounced as that of LMB (Figure 1d and e). Hence, NO can inhibit Mdm2mediated p53 nuclear export.

\section{NO induces ATR-dependent p53 phosphorylation on serine 15}

The activity of the N-terminal NES of p53 can be inhibited by phosphorylation on serine 15 (Ser15) of p53, as occurs after exposure to UV irradiation. ${ }^{27}$ Since NO blocks p53 nuclear export, we asked whether Ser15 phosphorylation is also involved in the effect of NO on p53. To that end, Clone 6 cells were treated with either GSNO or LMB, and p53 Ser15 phosphorylation were examined by Western blot analysis using a polyclonal antiphospho-Ser15 antibody. As shown in Figure 2a, GSNO induced substantial phosphorylation of p53

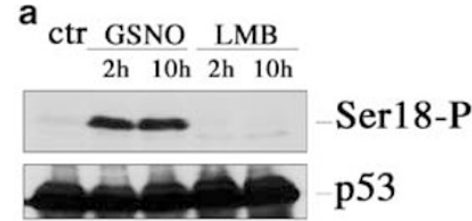

b

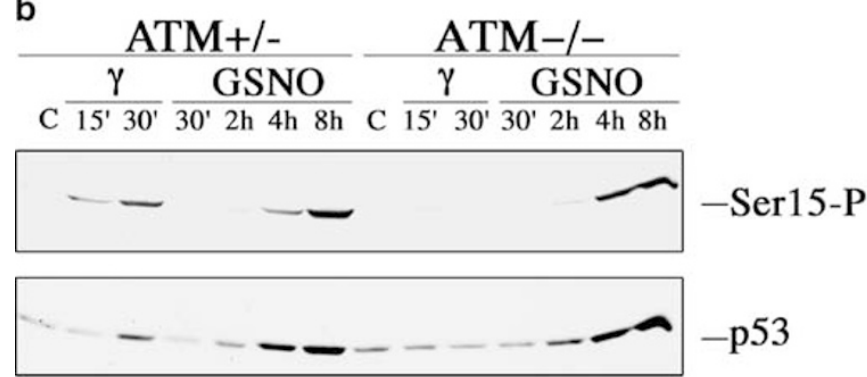

-Tubulin
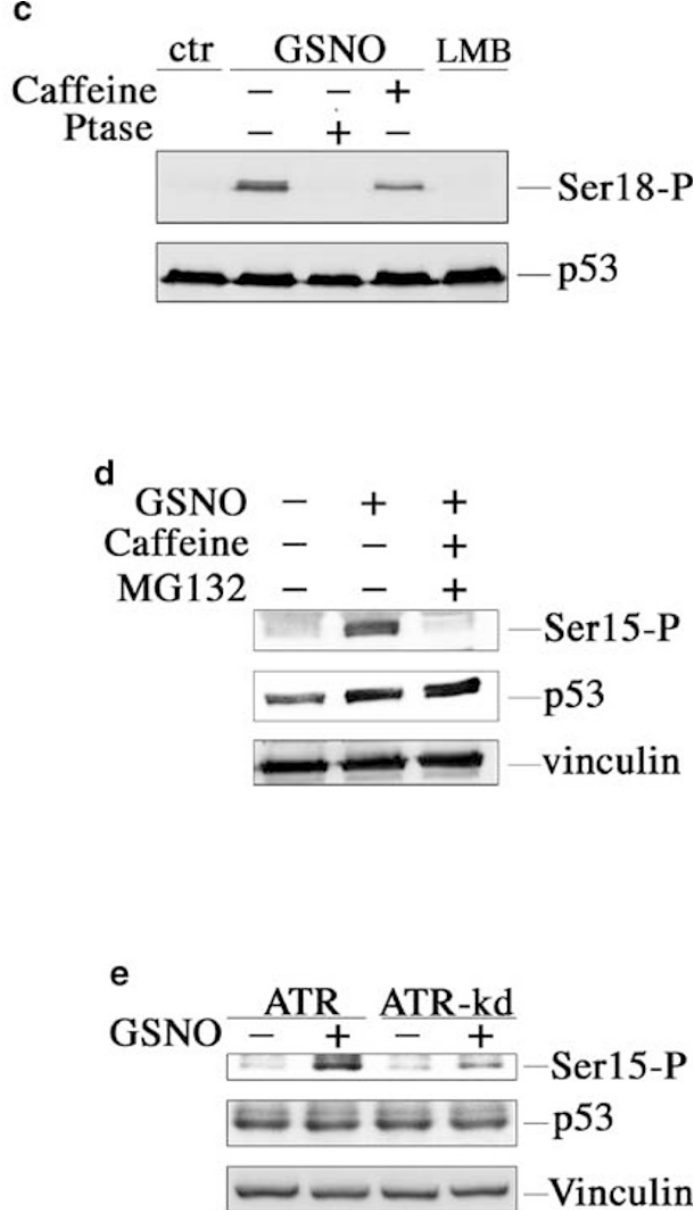

Figure 2 NO induces ATR-dependent p53 Ser15 phosphorylation. (a) Clone 6 cells were cultured at $37^{\circ} \mathrm{C}$ in the presence of $1 \mathrm{mM}$ GSNO or LMB (10 $\mathrm{ng} / \mathrm{ml}$ ) for the indicated periods. Phosphorylation of mouse p53 on Ser18 (equivalent to Ser15 of human p53) was monitored by Western blot analysis, using a polyclonal anti-Ser15-P antibody. (b) Human diploid fibroblasts heterozygous or homozygous for ATM gene mutations (ATM+/- and ATM-/-, respectively; see Materials and Methods) were treated with $1 \mathrm{mM} \mathrm{GSNO}$ or exposed to 4 Gy of gamma-irradiation $(\gamma)$, and harvested at the indicated times thereafter. Ser15 phosphorylation was monitored by Western blot analysis as in (a). (c) Clone 6 cells were cultured at $37^{\circ} \mathrm{C}$ in the presence of $1 \mathrm{mM}$ GSNO for $10 \mathrm{~h}$. When indicated, caffeine (5 mM) was added $1 \mathrm{~h}$ before GSNO Western blotting of mouse p53 and p53-Ser18-P were performed as in (a). One extract of GSNO-treated cells was incubated with alkaline phosphatase (Ptase) for $1 \mathrm{~h}$ at $37^{\circ} \mathrm{C}$ prior to electrophoretic analysis, to confirm that the anti-Ser15-P antibody was specific for phosphorylated p53 only. (d) ATM-/- human fibroblasts were treated with $1 \mathrm{mM}$ GSNO for $4 \mathrm{~h}$ in the presence or absence of caffeine $(5 \mathrm{mM})$ and MG132 $(25 \mu \mathrm{M})$. Western blot analysis of total p53 and p53-Ser15-P were done as in (a); vinculin served as a loading control. (e) HEK-293 cells were transfected with $10 \mu \mathrm{g}$ of expression plasmids encoding either wt ATR or kinase dead ATR (ATR-kd). At $48 \mathrm{~h}$ after transfection, cells were treated with $1 \mathrm{mM}$ GSNO for $4 \mathrm{~h}$. Detection of p53, p53-Ser15-P and vinculin was performed as in (d) 
on serine 18 (Ser 18), the mouse equivalent of human p53 Ser15 (note that the tsp53 in Clone 6 cells is of murine origin). Such an effect was not seen with LMB, although both agents promote to a similar extent the nuclear retention of p53 in these cells (see Figure 1a). This argues strongly that Ser18 phosphorylation is not a secondary consequence of the nuclear trapping of $p 53$, but rather may be playing a causative role in the inhibition of p53 nuclear export by NO. The latter conjecture is also supported by the observation that Ser18 phosphorylation is already maximal as early as $2 \mathrm{~h}$ after $\mathrm{NO}$ exposure (Figure 2a).

The ATM protein kinase is critical for the phosphorylation of $\mathrm{p} 53$ on Ser15 in response to ionizing radiation. ${ }^{50,51}$ However, as reported earlier, ${ }^{38}$ p53 activation by NO does not require ATM. To examine more directly the relation between NO-induced Ser15 phosphorylation and ATM, ATM heterozygous (ATM+l-) and ATM-deficient (ATM-l-) human fibroblasts were treated with GSNO for different durations, and the extent of Ser15 phosphorylation was monitored along with the levels of total p53. As seen in Figure $2 b$, GSNO induced similar profiles of p53 stabilization and Ser15 phosphorylation regardless of the difference in ATM status, indicating that p53 Ser15 phosphorylation by NO is ATM-independent. In contrast, $\gamma$-irradiation failed to elicit a rapid p53 response accompanied by p53 Ser15 phosphorylation in ATM-/- fibroblasts, in agreement with the literature. ${ }^{50,51}$

A likely candidate for mediating NO-induced p53 phosphorylation on Ser15 is the ATR (ATM and Rad3 related) protein kinase. This is because NO can generate single-strand DNA breaks, a type of damage shown to activate ATR, but not ATM. ${ }^{1,52,53}$ To test this idea we used caffeine, a selective inhibitor of ATR and ATM, but not of DNA-PK, ${ }^{52,53}$ another potential Ser15 kinase. As shown in Figure 2c, incubation with $5 \mathrm{mM}$ caffeine reversed to a large extent the NO-induced Ser15 phosphorylation of the tsp53 in Clone 6 . The inhibitory effect of caffeine was even more dramatic in several other cell types (e.g. Figure 2d). Hence, NO-induced Ser15 phosphorylation is predominantly because of caffeine-sensitive kinases.

The impact of caffeine on NO-induced p53 Ser15 phosphorylation was further investigated in ATM-/- fibroblasts. To maintain high levels of p53 in the presence of caffeine, the proteasome inhibitor MG132 was included in the appropriate culture medium. As seen in Figure 2d, caffeine abrogated very efficiently the NO-induced p53 Ser15 phosphorylation signal. Since these cells do not express functional ATM, this observation implicates ATR as the relevant caffeine-sensitive Ser15 kinase.

To establish formally the role of ATR in the induction of Ser15 phosphorylation by NO, we took advantage of a kinase-dead ATR mutant (ATR-kd), previously shown to act as a dominant-negative mutant for ATR activity. ${ }^{54,55}$ Expression plasmids for ATR and ATR-kd were transiently transfected into HEK293 cells, which enable high transfection efficiency. Substantial phosphorylation of p53 on Ser15 was induced by a $4 \mathrm{~h}$ GSNO treatment in cells transfected with wt ATR (Figure 2e). In contrast, very little Ser15 phosphorylation occurred when GSNO was applied to cells overexpressing ATR-kd. Taken together, the results in Figure 2 argue strongly that NO-induced p53 Ser15 phosphorylation is due to the action of the ATR kinase.

\section{ATR inhibition abolishes NO-induced p53 nuclear retention}

If Ser15 phosphorylation is important for the nuclear retention of p53 following exposure to $\mathrm{NO}$, one might predict that caffeine will abolish retention. This prediction was tested in Clone 6 cells, treated with $1 \mathrm{mM}$ GSNO for $4 \mathrm{~h}$ in the presence or absence of $50 \mathrm{mM}$ caffeine, added $1 \mathrm{~h}$ before GSNO. As predicted, caffeine completely abrogated $\mathrm{NO}$-induced nuclear retention of tsp53 at $37^{\circ} \mathrm{C}$ (Figure 3a).

To determine whether caffeine blocks also wtp53 nuclear retention, a similar experiment was performed with IMR32 cells. As shown in Figure 3b, caffeine prevented NO-induced p53 nuclear retention in these cells as well (Figure 3b). To further address the role of ATR in NO-induced p53 nuclear retention, fibroblasts derived from an ATM/p53 double knockout mouse (ap24) were cotransfected with tsp53 together with a plasmid encoding puromycin

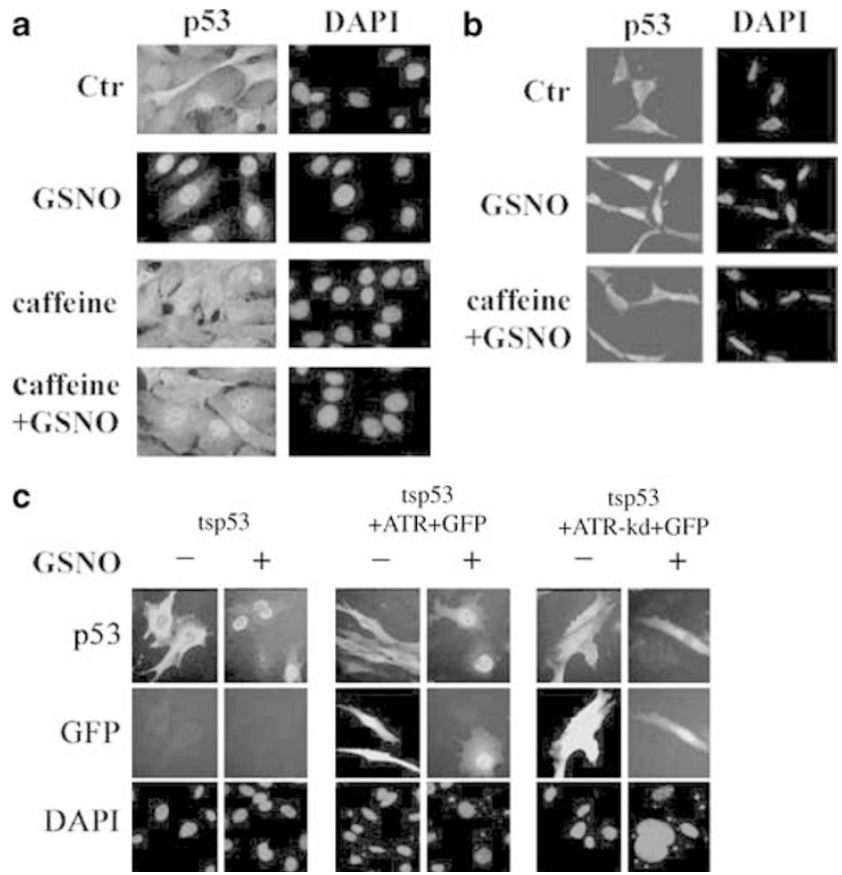

Figure 3 Inhibition of ATR abolishes NO-induced p53 nuclear retention. (a) Clone 6 cell, cultured at $37^{\circ} \mathrm{C}$, were treated with $1 \mathrm{mM}$ GSNO for $4 \mathrm{~h}$. Where indicated, caffeine $(50 \mathrm{mM})$ was added $1 \mathrm{~h}$ before addition of GSNO. Localization of the tsp53 was monitored as in Figure 1a. (b) IMR32 cells were treated as in (a). Localization of human p53 was as in Figure 1b. (c) ATM/p53-double knockout fibroblasts (ap24) were transfected with a murine tsp53 expression plasmid, together with a plasmid conferring puromycin resistance (pBabe-puro). Transfected cells were selected for $24 \mathrm{~h}$ in presence of $5 \mu \mathrm{g} / \mathrm{ml}$ puromycin. After two passages in the absence of puromycin, two cultures were cotransfected with DNA encoding either wt ATR (ATR; middle panel) or kinase-dead ATR (ATR-kd; right panel), together with a plasmid encoding GFP, whereas a third culture was left untransfected (left panel). The ATR plasmid DNA was in 10-fold excess over the GFP plasmid. After $36 \mathrm{~h}$, cells were treated with $0.5 \mathrm{mM}$ GSNO for $6 \mathrm{~h}$ p53 was detected by IF with CM5. GFP-positive cells are presumed to coexpress wt ATR or ATR-kd, as indicated 
resistance. Puromycin-resistant cells were next subjected to a second round of transfection with a GFP-expressing plasmid, together with DNA encoding either wt ATR or kinase-dead ATR (ATR-kd). Cells maintained at $37^{\circ} \mathrm{C}$ were then treated with $0.5 \mathrm{mM}$ GSNO for $6 \mathrm{~h}$, followed by staining for p53. As seen in Figure 3c, exposure to GSNO resulted in prominent nuclear translocation of p53 in the vast majority of cells transfected with wt ATR (see GFP-positive cells, middle panel), similar to what was seen in ap24 cells that had been subjected only to a single round of transfection with tsp53 (Figure 3c, left panel). By contrast, in the majority of the cells transfected with ATR-kd, NO-driven nuclear translocation of p53 was inhibited, resulting in substantial retention of the tsp53 in the cytoplasm (note GFP-positive cell in Figure 3c, right panel). These observations underscore the importance of ATR in NO-driven nuclear retention of $\mathrm{p} 53$.

In addition to its impact on nuclear localization, caffeine also interfered with NO-dependent stabilization of p53 and upregulation of steady-state p53 levels, as reflected by the weaker p53 staining, when compared to cells treated with GSNO alone (Figure 3b). Such attenuation of p53 staining was not seen in Clone 6 cells (Figure 3a), where p53 is constitutively overexpressed and GSNO does not lead to a significant change in its total amount (see Figure 2c). The ability of caffeine to interfere with p53 stabilization and Ser15 phosphorylation in response to NO was also confirmed directly, by Western blot analysis, in several cell types including MEFs, ATM-/- human fibroblasts and scid primary mouse fibroblasts (data not shown). Thus, NO-induced p53 stabilization and nuclear retention are both mediated by a caffeine-sensitive pathway, most certainly involving the activation of ATR.

\section{NO sensitizes neuroblastoma cells to induction of apoptosis by ionizing radiation}

The aberrant cytoplasmic sequestration of p53 in some tumors, including a significant fraction of neuroblastomas, ${ }^{44}$ has been reported to interfere with the induction of an efficient p53 response following exposure to DNA damage. ${ }^{45}$ This may impede the success of radiotherapy and DNA-damaging chemotherapy in the treatment of such tumors. The ability of $\mathrm{NO}$ to mobilize cytoplasmically sequestered p53 into the nucleus thus raised the possibility that NO might render cells derived from such tumors more sensitive to the apoptotic, p53-dependent action of DNA-damaging agents. This notion was investigated in IMR32 cells; the results are presented in Figure 4. Treatment of IMR32 cells with $1 \mathrm{mM}$ GSNO alone induced a measurable extent of apoptosis, which became more pronounced after relatively longer exposure times (see Figure $4 \mathrm{~b}, 48 \mathrm{~h}$ ). The ability of NO to elicit apoptosis is consistent with the finding that LMB, which like NO also promotes nuclear retention of p53, can trigger apoptosis in neuroblastoma cells. ${ }^{56}$ However, the extent of apoptosis was markedly increased when GSNO was combined with low-tomoderate doses of ionizing radiation (IR; 0.5-2 Gy), which on their own were rather inefficient in triggering apoptosis in this experimental system (Figure $4 \mathrm{a}$ and b). Similar results were
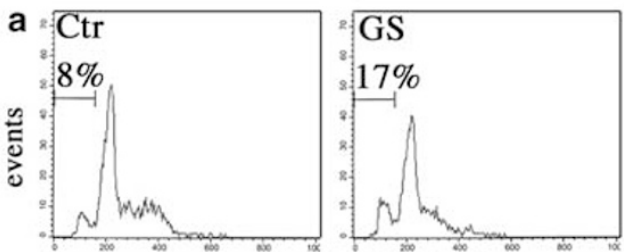

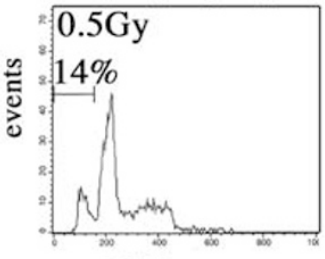

DNA content

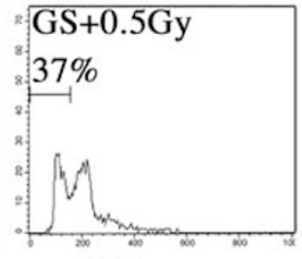

DNA content
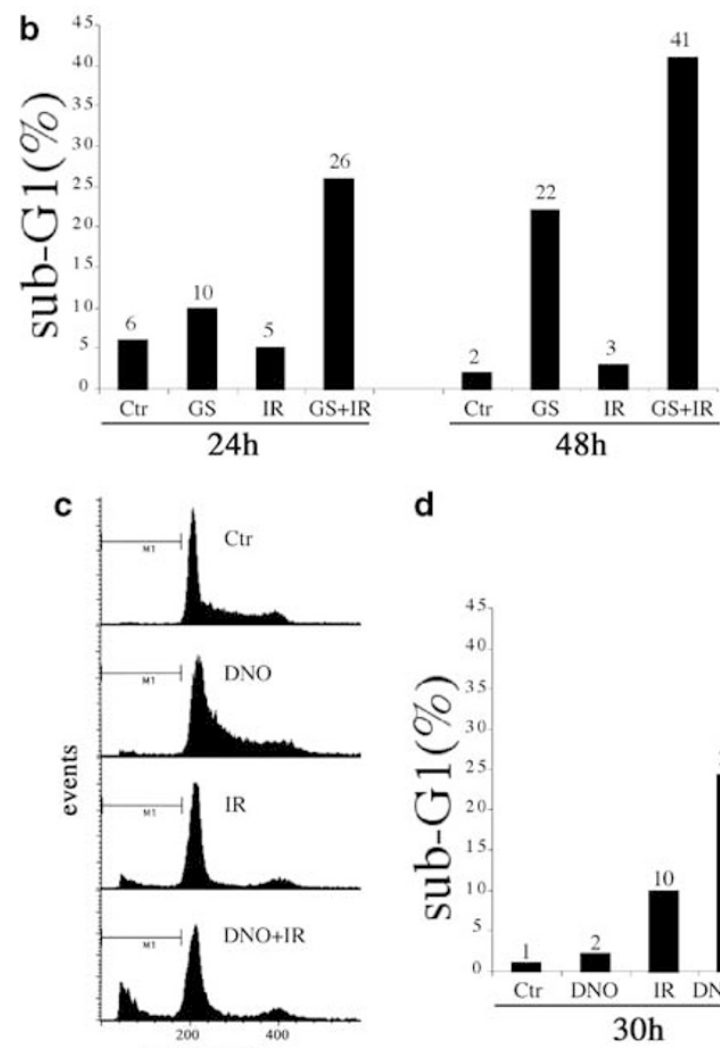

d

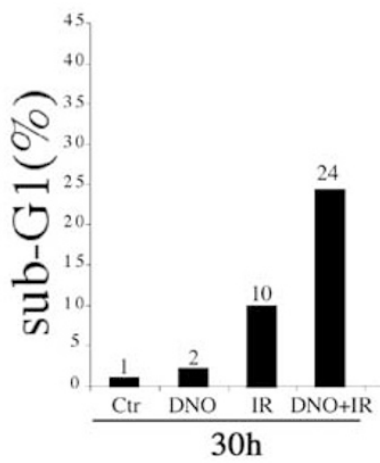

DNA content

Figure 4 NO sensitizes IMR32 cells to induction of apoptosis by ionizing radiation. IMR32 cells were plated at $0.5 \times 10^{6} \mathrm{cells} / 6 \mathrm{~cm}$ dish. In the experiments summarized in (b-d), cells were refed with fresh medium immediately prior to treatment. Cells were either left untreated (Ctr), or treated with the indicated combinations of $1 \mathrm{mM}$ GSNO (GS), $0.2 \mathrm{mM}$ DETA-NO (DNO) and gamma irradiation (0.5 Gy in (a) 2 Gy in (b) and 4 Gy in (c,d). GSNO was added to the culture $2 \mathrm{~h}$ before gamma irradiation, whereas DETA-NO was added $10 \mathrm{~h}$ before gamma irradiation. Cells in (a) were harvested $24 \mathrm{~h}$ after initiation of treatment, whereas cells in (b-d) were harvested either after $24 \mathrm{~h}$, $48 \mathrm{~h}$, or $30 \mathrm{~h}$, as indicated. Adherent and floating cells were combined, fixed and subjected to FACS analysis. Panels (a) and (b) represent three independent experiments, whereas panels (c) and (d) relate to the same experiment

obtained when DETA-NO was used as an NO donor: as seen in Figure $4 \mathrm{c}$ and d, pretreatment of IMR32 cells for $10 \mathrm{~h}$ with as little as $0.2 \mathrm{mM}$ DETA-NO increased by more than two-fold the extent of apoptosis induced by IR (4Gy). Hence, NO 
synergizes with IR to induce a greater exert of apoptosis in neuroblastoma cells harboring cytoplasmic $p 53$, implying that elevation of intracellular NO levels can sensitize such cells to apoptotic killing by radiation.

\section{Discussion}

The mechanisms underlying p53 activation by $\mathrm{NO}$ are not fully understood. Our recent data ${ }^{38}$ suggest that activation may involve at least two distinct components. At early times after exposure to NO, steady-state levels of Mdm2 drop markedly, enabling the initial accumulation of stable p53. Subsequently Mdm2 levels rise again, owing to the transactivation of the $m d m 2$ gene by the accumulated p53; yet, p53 remains stable, implying that it is refractory to the degradation-promoting effects of Mdm2. In the present study, we explored potential mechanisms that may underlie the resistance of p53 to Mdm2mediated degradation in NO-treated cells. We report that p53 stabilization by $\mathrm{NO}$ correlates with inhibition of p53 nuclear export, in a manner dependent on the activity of ATR. Of note, strong effects were already seen with as little as $100 \mu \mathrm{M}$ DETA-NO, a concentration reported to produce physiologically relevant steady-state amounts of NO. ${ }^{57,58}$ Exposure to NO gives rise to abasic sites within the DNA, subject to repair by the base excision repair (BER) mechanism, which involves formation of single-stranded DNA breaks (reviewed in Burney et al. ${ }^{1}$ ). Furthermore, NO concentrations in the micromolar range were shown to generate single-stranded DNA breaks. $^{59,60}$ It is thus likely that activation of ATR in NOtreated cells occurs in response to the introduction of singlestranded DNA breaks.

As shown here, NO strongly promotes the nuclear retention of p53, even under conditions where p53 is otherwise mostly cytoplasmic. This could be due either to dissociation of the interaction between p53 and its putative cytoplasmic anchoring proteins, or to inhibition of p53 nuclear export. Our data support the latter model, even though the two mechanisms are not mutually exclusive: like LMB, NO promotes nuclear accumulation of $\mathrm{p} 53$ in cells possessing a hyperactive p53 nuclear export system. ${ }^{41}$ Moreover, NO is capable of blocking Mdm2-driven nuclear export of p53. In agreement with the proposal that the effect of $\mathrm{NO}$ is exerted on the nuclear export rather than the cytoplasmic anchoring of p53, in vitro incubation of cytoskeleton-bound p53 with $4 \mathrm{mM}$ GSNO in the presence of reconstituted cellular extracts did not release any p53 from the cytoskeleton (data not shown). Interestingly, high concentrations of zinc, which protect cultured human neurons against apoptosis, do so partially by preventing the translocation of p53 into the nucleus. ${ }^{61}$ As shown here, NO-triggered mobilization of p53 into the nucleus augments apoptosis of neuroblastoma cells. Hence, controlled nuclear translocation of p53 may be a general mechanism for modulating apoptosis in cells of neuronal origin.

Nuclear retention of p53 is strongly correlated with phosphorylation of p53 on Ser15, and both are induced by NO in an ATR-dependent manner. NO-induced Ser15 phosphorylation has already been described. ${ }^{34}$ It has recently been reported that induction of p53 by $\mathrm{NO}$ in chondrocytes is mediated via the p38 kinase, and that p38 directly phosphorylates p53 on Ser15. ${ }^{62}$ However, in our hands, the extent of NO-induced Ser15 phosphorylation was unaffected by the specific p38 inhibitor SB203580 (20 $\mu \mathrm{M}$ final concentration; data not shown). This, along with the efficient blockage of Ser15 phosphorylation by caffeine and by dominant negative ATR, argue against a significant contribution of p38 to the activation of p53 in the experimental systems studied here. It nevertheless remains possible that the pathways leading to p53 activation vary among different cell types, with p38 being more critical in chondrocytes.

Ser15 phosphorylation may be critical for the efficient inhibition of p53 nuclear export. Although there still is some ambiguity with regard to the regulation of p53 nuclear export, the presently available information is consistent with the notion that p53 possesses two NESs, one within its C-terminal oligomerization domain ${ }^{41}$ and the other within its $\mathrm{N}$-terminal domain, encompassing Ser15. ${ }^{27}$ In active tetrameric $p 53$, the C-terminal NES may normally be inaccessible, becoming exposed upon Mdm2-mediated ubiquitination of p53 on Cterminal lysine residues. ${ }^{41,48,49,63,64}$ Such ubiquitination may take place constitutively in the absence of p53-activating stress signals. Similarly, the N-terminal NES is believed to be accessible in nonstressed cells. ${ }^{27}$ For efficient nuclear export of $p 53$, both NES elements may have to be operative. This may pertain in the absence of stress, thereby enabling p53 to reside largely within the cytoplasm, at least during part of the cell cycle. ${ }^{65}$ Stress signals may incapacitate both NES elements; in the case of the C-terminal NES, this is likely to be achieved by promotion of tetramerization and inhibition of ubiquitination, ${ }^{41,48,49,63,64}$ while $\mathrm{N}$-terminal NES inactivation involves phosphorylation on Ser15 and Ser20. ${ }^{27} \mathrm{NO}$ appears to be no exception: it both reduces p53 ubiquitination ${ }^{38}$ and promotes Ser15 phosphorylation (this study).

The precise relation between Ser15 phosphorylation and p53 degradation, as well as between nuclear export and p53 degradation, remains unclear. While phosphorylation of p53 on $\mathrm{N}$-terminal residues usually increases substantially under conditions where p53 is stabilized, mutational analysis implies that this alone may not suffice to prevent p53 degradation. ${ }^{26,66,67}$ Similarly, while stress-induced stabilized p53 always accumulates in the nucleus, the dogma that ubiquitinated p53 can be degraded only in the cytoplasm has been recently questioned by showing that p53 can be degraded efficiently by nuclear proteasomes, as long as Mdm2 is also retained in the nucleus. ${ }^{68,69}$ Hence, p53 stabilization may require a combination of several coordinated events. In the case of NO, these events appear to be mediated in great part by ATR

We show that NO can sensitize cells to p53-dependent apoptosis. The apoptotic effects of $\mathrm{NO}$ have already been shown to rely on $\mathrm{p53} .^{28}$ We show that NO can cooperate with other p53-activating signals, such as DNA damage, to maximize the contribution of p53 to cell killing. This may be of particular relevance in cases where the endogenous p53, albeit wt by sequence, is relatively refractory to activation by DNA damage. As shown here, NO confers upon neuroblastoma cells increased sensitivity to killing by low doses of radiation, to which they are otherwise relatively nonresponsive. Hence, agents that elevate NO production in vivo may 
potentially increase the efficacy of DNA-damaging anticancer treatments in the eradication of neuroblastoma and possibly additional types of tumors. Such strategy may further benefit from the fact that the effect of NO on p53 function and apoptotic activity is cell type-specific, to the extent that in some cases NO can actually downregulate p53 activity. ${ }^{33,70-}$ 72 This, along with indications that the p53-dependent apoptotic effect of $\mathrm{NO}$ is augmented in the absence of a functional $\mathrm{Rb}$-mediated growth arrest pathway, ${ }^{73}$ as occurs in many tumors, may provide an opportunity for selective killing of tumor cells in an in vivo context.

\section{Materials and Methods}

\section{Cells and tissue culture}

Clone 6 cells are rat embryonic fibroblasts transformed by a combination of Ras and a temperature-sensitive mouse p53 mutant, p53 Val135. ${ }^{42,43}$ IMR32 is a neuroblastoma cell line expressing wtp53, which is mainly localized in the cytoplasm. ${ }^{44,45}$ ap24 is a cell line derived from a p53/ATMdouble knockout mouse embryonic fibroblasts. ${ }^{74}$ Clone 6 cells, ap24 cells, IMR32 cells, U2-OS human osteosarcoma cells, and HEK-293 cells were maintained at $37^{\circ} \mathrm{C}$ in Dulbecco's modified Eagle's medium (DMEM) supplemented with $10 \%$ heat-inactivated fetal bovine serum (FBS, Sigma) and antibiotics. AG03058 (ATM-/-, wtp53) cells, derived from an AT patient (daughter), and AG03057 (ATM+/-, wtp53) cells, derived from the healthy mother of the same patient, were obtained from the National Institute of General Medical Sciences Human Genetic Mutant Cell Repository (Coriell Institute, Camden, NJ, USA) and were maintained in MEM supplemented with $20 \%$ nonheat-inactivated FBS.

\section{Chemicals}

GSNO (S-nitroso-glutathione) and DETA-NO (NOC-18; (Z)-1-[2-(2aminoethyl)- $N$-(2-ammonioethyl)amino]diazen-1-ium-1,2-diolate) (Alexis Biochemicals) were dissolved in PBS- - - at a concentration of $50 \mathrm{mM}$ and stored at $-80^{\circ} \mathrm{C}$ in small aliquots. MG132 (Calbiochem) was dissolved in DMSO at a concentration of $50 \mathrm{mM}$ and used at a final concentration of $25 \mu \mathrm{M}$. Leptomycin B (LMB) (Sigma) was dissolved in ethanol at $10 \mu \mathrm{g} / \mathrm{ml}$ and stored at $-80^{\circ} \mathrm{C}$ and used at $10 \mathrm{ng} / \mathrm{ml}$. Protease and phosphatase inhibitor cocktails were purchased from Sigma and used at $1: 500$ and $1: 200$ dilutions, respectively.

\section{Transfections}

U2-OS cells were plated at $0.5 \times 10^{6} / 6 \mathrm{~cm}$ plate and transfected with the aid of the JetPEI reagent (PolyPlus Transfection, France) according to the manufacturer's instructions. Transfection efficiencies were typically above 50-70\%. GSNO treatment was performed $18 \mathrm{~h}$ after transfection.

\section{Antibodies, indirect immunofluorescence and Western blot analysis}

Polyclonal anti-human p53 CM1 (Novocastra Laboratories Ltd), polyclonal anti-mouse p53 CM5 (Novocastra Laboratories Ltd), and polyclonal antiHA (Santa Cruz) antibodies were used for immunofluorescence microscopy. p53 Ser15 phosphorylation was detected by direct Western blotting with a polyclonal anti-p53-PSer15 antibody generated by immunizing rabbits with a Ser15-phospho-peptide followed by immunoaffinity chromatographic purification. ${ }^{75}$ Monoclonal antivinculin antibody was a gift from B Geiger (Weizmann Institute). Indirect immunofluorescence microscopy and Western blot analysis were performed as described previously. $^{24}$

\section{Flow cytometry}

IMR32 cells were seeded at a density of $1 \times 10^{6} / 10 \mathrm{~cm}$ dish. After 2 days, the medium was replaced and some of the cells were treated with $1 \mathrm{mM}$ GSNO or $0.2 \mathrm{mM} \mathrm{DETA-NO}$ at $37^{\circ} \mathrm{C}$ for 2 or $10 \mathrm{~h}$, respectively, at which time they were exposed to gamma irradiation. Irradiated cells were incubated at $37^{\circ} \mathrm{C}$ for 24 or $48 \mathrm{~h}$, in the continuous presence of GSNO or DETA-NO where appropriate. Floating and attached cells were collected and combined together. Propidium iodide (Sigma) staining was used for determination of DNA content, as described elsewhere. ${ }^{76}$

\section{Acknowledgments}

We thank Dr. D Michael for helpful discussions, Dr. Y Taya for the antiSer15-P antibody, Dr. M Schwab and Dr. Y Shiloh and for IMR32 and ap24 cells, respectively, Dr. M Kastan for pCDNA3-ATR-wt and pCDNA3ATR-kd plasmids and Dr. B Geiger for anti-vinculin antibodies. This work was supported in part by grant R01 CA 40099 from the National Cancer Institute (USA), The USA-Israel Binational Science Foundation, the Kadoorie Charitable Foundations, the Center for Excellence Program of the Israel Science Foundation, and the Yad Abraham Center for Cancer Diagnosis and Therapy.

\section{References}

1. Burney S, Caulfield JL, Niles JC, Wishnok JS and Tannenbaum SR (1999) The chemistry of DNA damage from nitric oxide and peroxynitrite. Mutat. Res. 424: 37-49

2. Hess DT, Matsumoto A, Nudelman R and Stamler JS (2001) S-nitrosylation: spectrum and specificity. Nat. Cell. Biol. 3: E46-E49

3. Brune B and von Knethen A (2002) The role of nitric oxide and cyclooxygenase-2 in attenuating apoptosis. J. Environ. Pathol. Toxicol. Oncol. 21: 103-112

4. Schmidt HH and Walter U (1994) NO at work. Cell 78: 919-925

5. Zweier JL, Samouilov A and Kuppusamy P (1999) Non-enzymatic nitric oxide synthesis in biological systems. Biochim. Biophys. Acta. 1411: 250-262

6. Melillo G, Musso T, Sica A, Taylor LS, Cox GW and Varesio L (1995) A hypoxia-responsive element mediates a novel pathway of activation of the inducible nitric oxide synthase promoter. J. Exp. Med. 182: 1683-1693

7. Melillo G, Taylor LS, Brooks A, Musso T, Cox GW and Varesio L (1997) Functional requirement of the hypoxia-responsive element in the activation of the inducible nitric oxide synthase promoter by the iron chelator desferrioxamine. J. Biol. Chem. 272: 12236-12243

8. Bargonetti J and Manfredi JJ (2002) Multiple roles of the tumor suppressor p53. Curr. Opin. Oncol. 14: 86-91

9. Michael $D$ and Oren $M(2002)$ The $p 53$ and Mdm2 families in cancer. Curr. Opin. Genet. Dev. 12: 53-59

10. Prives $C$ and Hall PA (1999) The p53 pathway. J. Pathol. 187: 112-126

11. Vogelstein B, Lane $D$ and Levine AJ (2000) Surfing the p53 network. Nature 408: $307-310$

12. Vousden KH and Woude GF (2000) The ins and outs of p53. Nat. Cell. Biol. 2: E178-E180

13. Woods DB and Vousden KH (2001) Regulation of p53 function. Exp. Cell. Res. 264: $56-66$

14. Haupt Y, Maya R, Kazaz A and Oren M (1997) Mdm2 promotes the rapid degradation of p53. Nature 387: 296-299

15. Kubbutat MH, Jones SN and Vousden KH (1997) Regulation of p53 stability by Mdm2. Nature 387: 299-303 
16. Honda $\mathrm{R}$, Tanaka $\mathrm{H}$ and Yasuda $\mathrm{H}$ (1997) Oncoprotein MDM2 is a ubiquitin ligase E3 for tumor suppressor p53. FEBS Lett. 420: 25-27

17. Honda R and Yasuda H (1999) Association of p19(ARF) with Mdm2 inhibits ubiquitin ligase activity of Mdm2 for tumor suppressor p53. EMBO J. 18: 22-27

18. Fang S, Jensen JP, Ludwig RL, Vousden KH and Weissman AM (2000) Mdm2 is a RING finger-dependent ubiquitin protein ligase for itself and p53. J. Biol. Chem. 275: 8945-8951

19. Fuchs SY, Fried VA and Ronai Z (1998) Stress-activated kinases regulate protein stability. Oncogene 17: 1483-1490

20. Oren M (1999) Regulation of the p53 tumor suppressor protein. J. Biol. Chem. 274: 36031-36034

21. Ashcroft M, Taya $Y$ and Vousden KH (2000) Stress signals utilize multiple pathways to stabilize p53. Mol. Cell. Biol. 20: 3224-3233

22. Sherr CJ and Weber JD (2000) The ARF/p53 pathway. Curr. Opin. Genet. Dev. 10: $94-99$

23. Lowe SW (1999) Activation of $p 53$ by oncogenes. Endocr. Relat. Cancer 6: 4548

24. Damalas A, Kahan S, Shtutman M, Ben-Ze'ev A and Oren M (2001) Deregulated beta-catenin induces a p53- and ARF-dependent growth arrest and cooperates with Ras in transformation. EMBO J. 20: 4912-4922

25. Hirao A, Kong YY, Matsuoka S, Wakeham A, Ruland J, Yoshida H, Liu D, Elledge SJ and Mak TW (2000) DNA damage-induced activation of p53 by the checkpoint kinase Chk2. Science 287: 1824-1827

26. Unger T, Sionov RV, Moallem E, Yee CL, Howley PM, Oren M and Haupt $Y$ (1999) Mutations in serines 15 and 20 of human p53 impair its apoptotic activity. Oncogene 18: 3205-3212

27. Zhang $Y$ and Xiong $Y$ (2001) A p53 amino-terminal nuclear export signal inhibited by DNA damage- induced phosphorylation. Science 292: 1910-1915

28. Messmer UK, Ankarcrona M, Nicotera P and Brune B (1994) p53 expression in nitric oxide-induced apoptosis. FEBS Lett. 355: 23-26

29. Forrester K, Ambs S, Lupold SE, Kapust RB, Spillare EA, Weinberg WC Felley-Bosco E, Wang XW, Geller DA, Tzeng E, Billiar TR and Harris CC (1996) Nitric oxide-induced p53 accumulation and regulation of inducible nitric oxide synthase expression by wild-type p53. Proc. Natl. Acad. Sci. USA 93: 2442-2447

30. Ho YS, Wang YJ and Lin JK (1996) Induction of p53 and p21/WAF1/CIP1 expression by nitric oxide and their association with apoptosis in human cancer cells. Mol. Carcinog. 16: 20-31

31. Matsumoto $\mathrm{H}$ et al. (1999) Intercellular signaling initiated by nitric oxide produced in heat-shocked human glioblastoma cells. Nitric Oxide 3: 180-189

32. Brune B, von Knethen A and Sandau KB (2001) Transcription factors p53 and HIF-1alpha as targets of nitric oxide. Cell Signal 13: $525-533$

33. Umansky V and Schirrmacher V (2001) Nitric oxide-induced apoptosis in tumor cells. Adv. Cancer. Res. 82: 107-131

34. Nakaya N, Lowe SW, Taya Y, Chenchik A and Enikolopov G (2000) Specific pattern of p53 phosphorylation during nitric oxide-induced cell cycle arrest. Oncogene 19: 6369-6375

35. Ambs S, Bennett WP, Merriam WG, Ogunfusika MO, Oser SM, Harrington AM, Shields PG, Felley-Bosco E, Hussain SP and Harris CC (1999) Relationship between p53 mutations and inducible nitric oxide synthase expression in human colorectal cancer. J. Natl. Cancer Inst. 91: 86-88

36. Ambs S, Hussain SP and Harris CC (1997) Interactive effects of nitric oxide and the p53 tumor suppressor gene in carcinogenesis and tumor progression. FASEB J. 11: 443-448

37. Lala PK and Chakraborty C (2001) Role of nitric oxide in carcinogenesis and tumour progression. Lancet Oncol. 2: 149-156

38. Wang X, Michael D, de Murcia G and Oren M (2002) p53 activation by nitric oxide involves down-regulation of Mdm2. J. Biol. Chem. 26: 26

39. Shaulsky G, Goldfinger N, Ben-Ze'ev A and Rotter V (1990) Nuclear accumulation of $p 53$ protein is mediated by several nuclear localization signals and plays a role in tumorigenesis. Mol. Cell. Biol. 10: 6565-6577

40. Liang SH and Clarke MF (1999) A bipartite nuclear localization signal is required for $p 53$ nuclear import regulated by a carboxyl-terminal domain. $\mathrm{J}$ Biol. Chem. 274: 32699-32703

41. Stommel JM, Marchenko ND, Jimenez GS, Moll UM, Hope TJ and Wahl GM (1999) A leucine-rich nuclear export signal in the p53 tetramerization domain: regulation of subcellular localization and $p 53$ activity by NES masking. EMBO J. 18: $1660-1672$
42. Michalovitz D, Halevy $O$ and Oren M (1990) Conditional inhibition of transformation and of cell proliferation by a temperature-sensitive mutant of p53. Cell 62: 671-680

43. Ginsberg D, Michael-Michalovitz D and Oren M (1991) Induction of growth arrest by a temperature-sensitive p53 mutant is correlated with increased nuclear localization and decreased stability of the protein. Mol. Cell. Biol. 11: 582-585

44. Moll UM, LaQuaglia M, Benard J and Riou G (1995) Wild-type p53 protein undergoes cytoplasmic sequestration in undifferentiated neuroblastomas but not in differentiated tumors. Proc. Natl. Acad. Sci. USA 92: 4407-4411

45. Moll UM, Ostermeyer AG, Haladay R, Winkfield B, Frazier M and Zambetti G (1996) Cytoplasmic sequestration of wild-type p53 protein impairs the $G 1$ checkpoint after DNA damage. Mol. Cell. Biol. 16: 1126-1137

46. Morley D and Keefer LK (1993) Nitric oxide/nucleophile complexes: a unique class of nitric oxide- based vasodilators. J. Cardiovasc. Pharmacol. 22(Suppl 7): S3-S9

47. Roth J, Dobbelstein M, Freedman DA, Shenk T and Levine AJ (1998) Nucleocytoplasmic shuttling of the hdm2 oncoprotein regulates the levels of the p53 protein via a pathway used by the human immunodeficiency virus rev protein. EMBO J. 17: 554-564

48. Boyd SD, Tsai KY and Jacks T (2000) An intact HDM2 RING-finger domain is required for nuclear exclusion of p53. Nat. Cell. Biol. 2: 563-568

49. Geyer RK, Yu ZK and Maki CG (2000) The MDM2 RING-finger domain is required to promote p53 nuclear export. Nat. Cell. Biol. 2: 569-573

50. Banin S, Moyal L, Shieh S, Taya Y, Anderson CW, Chessa L, Smorodinsky NI, Prives C, Reiss Y, Shiloh Y and Ziv Y (1998) Enhanced phosphorylation of p53 by ATM in response to DNA damage. Science 281: 1674-1677

51. Canman CE, Lim DS, Cimprich KA, Taya Y, Tamai K, Sakaguchi K, Appella E, Kastan MB and Siliciano JD (1998) Activation of the ATM kinase by ionizing radiation and phosphorylation of p53. Science 281: 1677-1679

52. Hall-Jackson CA, Cross DA, Morrice N and Smythe C (1999) ATR is a caffeinesensitive, DNA-activated protein kinase with a substrate specificity distinct from DNA-PK. Oncogene 18: 6707-6713

53. Sarkaria JN, Busby EC, Tibbetts RS, Roos P, Taya Y, Karnitz LM and Abraham RT (1999) Inhibition of ATM and ATR kinase activities by the radiosensitizing agent, caffeine. Cancer Res. 59: 4375-4382

54. Cliby WA, Roberts CJ, Cimprich KA, Stringer CM, Lamb JR, Schreiber SL and Friend SH (1998) Overexpression of a kinase-inactive ATR protein causes sensitivity to DNA-damaging agents and defects in cell cycle checkpoints. EMBO J. 17: 159-169

55. Tibbetts RS, Brumbaugh KM, Williams JM, Sarkaria JN, Cliby WA, Shieh SY, Taya Y, Prives C and Abraham RT (1999) A role for ATR in the DNA damageinduced phosphorylation of p53. Genes Dev. 13: 152-157

56. Smart P, Lane EB, Lane DP, Midgley C, Vojtesek B and Lain S (1999) Effects on normal fibroblasts and neuroblastoma cells of the activation of the p53 response by the nuclear export inhibitor leptomycin B. Oncogene 18: 73787386

57. Shami PJ, Sauls DL and Weinberg JB (1998) Schedule and concentrationdependent induction of apoptosis in leukemia cells by nitric oxide. Leukemia 12: 1461-1466

58. Pasto M, Serrano E, Urocoste E, Barbacanne MA, Guissani A, Didier A, Delisle MB, Rami J and Arnal JF (2001) Nasal polyp-derived superoxide anion: dosedependent inhibition by nitric oxide and pathophysiological implications. Am. J. Respir. Crit. Care. Med. 163: 145-151

59. Tamir S, Burney S and Tannenbaum SR (1996) DNA damage by nitric oxide. Chem. Res. Toxicol. 9: 821-827

60. Lin W, Wei X, Xue H, Kelimu M, Tao R, Song Y and Zhou Z (2000) Study on DNA strand breaks induced by sodium nitroprusside, a nitric oxide donor, in vivo and in vitro. Mutat. Res. 466: 187-195

61. VanLandingham JW, Fitch CA and Levenson CW (2002) Zinc inhibits the nuclear translocation of the tumor suppressor protein p53 and protects cultured human neurons from copper-induced neurotoxicity. Neuromolecular. Med. 1: 171-182

62. Kim SJ, Hwang SG, Shin DY, Kang SS and Chun JS (2002) p38 kinase regulates nitric oxide-induced apoptosis of articular chondrocytes by accumulating p53 via NFkappa B-dependent transcription and stabilization by serine-15 phosphorylation. J. Biol. Chem. 
63. Inoue T, Geyer RK, Howard D, Yu ZK and Maki CG (2001) MDM2 can promote the ubiquitination, nuclear export, and degradation of p53 in the absence of direct binding. J. Biol. Chem. 276: 45255-45260

64. Maki CG (1999) Oligomerization is required for p53 to be efficiently ubiquitinated by MDM2. J. Biol. Chem. 274: 16531-16535

65. Shaulsky G, Ben-Ze'ev A and Rotter V (1990) Subcellular distribution of the p53 protein during the cell cycle of Balb/c 3T3 cells. Oncogene 5: 1707-1711

66. Ashcroft M, Kubbutat MH and Vousden KH (1999) Regulation of p53 function and stability by phosphorylation. Mol. Cell. Biol. 19: 1751-1758

67. Blattner C, Tobiasch E, Litfen M, Rahmsdorf HJ and Herrlich P (1999) DNA damage induced p53 stabilization: no indication for an involvement of p53 phosphorylation. Oncogene 18: 1723-1732

68. Xirodimas DP, Stephen CW and Lane DP (2001) Cocompartmentalization of p53 and Mdm2 is a major determinant for Mdm2- mediated degradation of p53. Exp. Cell. Res. 270: 66-77

69. Yu ZK, Geyer RK and Maki CG (2000) MDM2-dependent ubiquitination of nuclear and cytoplasmic P53. Oncogene 19: 5892-5897

70. Martinez-Mier G, Toledo-Pereyra LH, Bussell S, Gauvin J, Vercruysse G, Arab A, Harkema JR, Jordan JA and Ward PA (2000) Nitric oxide diminishes apoptosis and p53 gene expression after renal ischemia and reperfusion injury. Transplantation 70: 1431-1437
71. Chen Y, Stanford A, Simmons RL, Ford HR and Hoffman RA (2001) Nitric oxide protects thymocytes from gamma-irradiation-induced apoptosis in correlation with inhibition of p53 upregulation and mitochondrial damage. Cell. Immunol. 214: 72-80

72. Chazotte-Aubert L, Pluquet $O$, Hainaut $P$ and Ohshima $H$ (2001) Nitric oxide prevents gamma-radiation-induced cell cycle arrest by impairing p53 function in MCF-7 cells. Biochem. Biophys. Res. Commun. 281: 766-771

73. Yang F, von Knethen A and Brune B (2000) Modulation of nitric oxide-evoked apoptosis by the p53-downstream target p21(WAF1/CIP1). J. Leukoc. Biol. 68: 916-922

74. Westphal $\mathrm{CH}$, Hoyes KP, Canman CE, Huang X, Kastan MB, Hendry JH and Leder $P$ (1998) Loss of atm radiosensitizes multiple p53 null tissues. Cancer Res. 58: 5637-5639

75. Shieh SY, Ikeda M, Taya Y and Prives C (1997) DNA damage-induced phosphorylation of p53 alleviates inhibition by MDM2. Cell 91: 325-334

76. Israeli D, Tessler E, Haupt $Y$, Elkeles A, Wilder S, Amson R, Telerman A and Oren M (1997) A novel p53-inducible gene, PAG608, encodes a nuclear zinc finger protein whose overexpression promotes apoptosis. EMBO J. 16: 43844392 